\title{
Morphometry study of pedicle for sacral screw fixation in Navi Mumbai population
}

\author{
Pravin R Rathod ${ }^{1}$, Santhi P Rathod ${ }^{2, *}$
}

${ }^{\mathbf{1}}$ Assistant Professor, Dept. of Anatomy, M.G.M Medical College, Navi Mumbai, Maharashtra, ${ }^{\mathbf{2}}$ Assistant Lecturer, Dept. of Biochemistry, Terna Medical College, Navi Maumbai, Maharashtra, India

\section{*Corresponding Author: Santhi P Rathod}

Email: santhipravin3@gmail.com

\begin{abstract}
An extensive review of the literature has revealed a limited pedicle study of the sacrum in Indian population. The present study analyses a very significant variation in the values, as regards the racial/ regional differences. Our study cover morphometric details of the 1 st pedicle of sacrum for pedicle screw placement. We intend to study for safe entry of pedicle screw including finding the screw depth in Navi Mumbai population.

Boucher in 1959 was the first to use pedicle screws. There has been an almost continuous development in the field of spinal instrumentation by various surgeons.

Materials and Methods: The study was done on 30 dry human sacra and 30 cadaver sacral bones which were collected from Department of Anatomy, M.G.M. Medical College, and Terna medical college.

Result: No significant difference in posterior pedicle height was seen in both genders. Anteroposterior length and width were higher on both sides in males. Anteroposterior length of alae on both sides in both genders were of almost of equal thickness.

Conclusion: Our study brings forth valuable data from a population of Navi Mumbai, which can be of use for operating surgeons and interventionists. Our study revealed racial and regional variation with a comparison to other country studies.
\end{abstract}

Keywords: Pedicle study, Sacrum, Morphometry, Screw fixation.

\section{Introduction}

The S1 pedicle is fairly different from the other spinal pedicles. Medial to the pedicle is the epidural space containing important nerve roots and dural sac. Close to the lateral and superior aspects of the pedicle is the nerve root from the previous segment. The iliac vessels and their branches lay laterally along sacral ala. ${ }^{1}$ In the midline of the sacrum, a variable middle sacral artery can lies directly anterior to the $S_{1}$ vertebral body. This is the danger area if the cortical screw is penetrated hitting the artery. ${ }^{2}$

Pedicle width is the perpendicular distance from the lateral end of the sacral canal to line joining the anterior to posterior notches of cortex at the pedicle (ref Fig. 1). The pedicle width helps to make partition between the sacral canal and lateral nonimportant area, which can be chosen for screw placement. The entry of pedicle screw should be directed anteromedially reaching the 1st vertebral body cortex for safe placement. The pedicle width is the minimum distance to assess the thickness of the pedicle screw. ${ }^{3}$

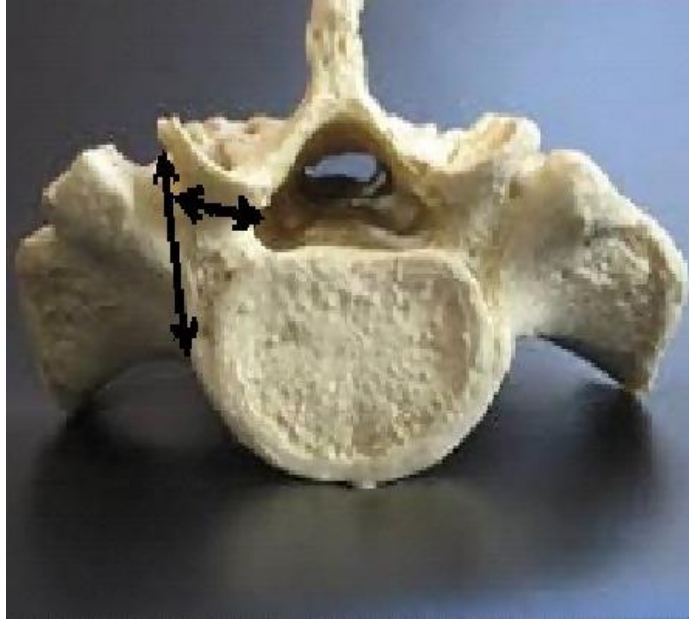

Fig. 1: Pedicle width

Pedicle screw placement is done under the fluoroscopic guidance and computerized guided technique now a day's keeping in view of the important relation of the pedicle.

\section{Objective of Research}

1. Study morphometry of first sacral pedicle.

2. Study gender differences of the first pedicle.

3. Compare study with another pedicle study.

\section{Materials and Methods}

Study Area: M.G.M. Medical College at Anatomy Department after ethical clearance certificate from MGMIHS. 
Study Sample: The Study was carried on 30 dry human sacra and 30 cadaver sacral bones which were collected from Department of Anatomy, M.G.M. Medical College, and Terna Medical College.

These specimens were divided into half male and half female, i.e. 15 male and 15 female dry and cadaveric specimens.

Inclusion Criteria: Only sacra with complete sacral hiatus were taken for the present study.

\section{Exclusion Criteria}

1. Damaged, mutilated and deformed sacra were excluded.

2. Sacra exhibiting variations were not included in taking measurements.
Parameters considered for the collection of data $1^{\text {st }}$ sacral pedicle measurement which includes

1. Anterior vertebral height

2. Posterior pedicle height

3. Antero-Posterior pedicle length

4. Pedicle width

5. Antero-Posterior diameter of sacral ala at the lateral margin of the posterior sacral foramen.

\section{Observations and Results}

1. Anterior Vertebral Height: It is the measurement taken between the superior and inferior border of the $1^{\text {st }}$ sacral vertebra on anterior aspect.

Table 1: Anterior vertebral height (mm)

\begin{tabular}{|l|c|c|c|c|}
\hline \multicolumn{3}{|l|}{ SD-Standard deviation } & \multicolumn{3}{c|}{ P value-Probability value } \\
\hline Gender & No. & Mean & SD & P-value \\
\hline Male & 30 & 27.0 & 2.9 & \multirow{0}{*}{$\mathbf{0 . 6 6}$} \\
\hline Female & 30 & 27.5 & 2.7 & \\
\hline
\end{tabular}

2. Posterior Pedicle Height (Fig. 2): It is the distance between superior border of the base of the pedicle and the superior border of the $1^{\text {st }}$ dorsal sacral foramen.

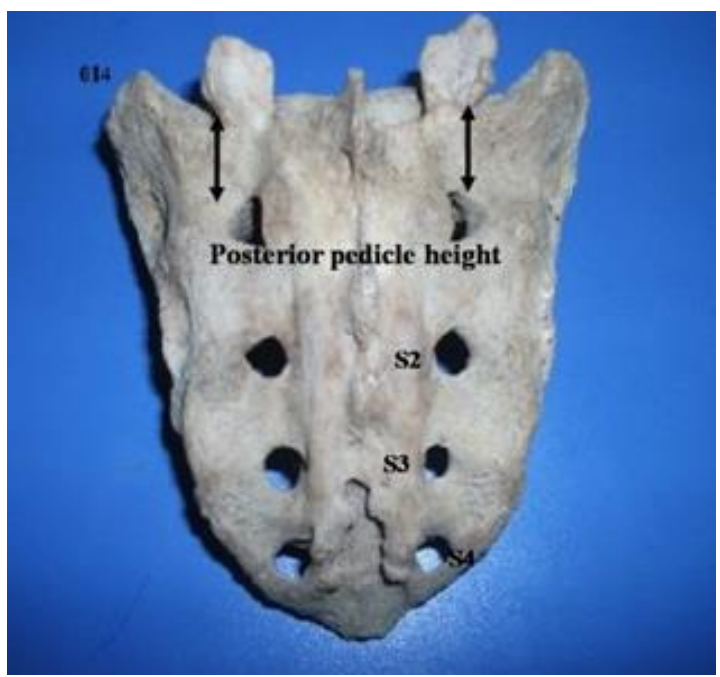

Fig. 2: Posterior pedicle height (014)-Specimen number, (S)-dorsal sacral foramen)

Table 2: Posterior pedicle height $(\mathrm{mm})$

\begin{tabular}{|c|c|c|c|c|c|c|c|}
\hline \multicolumn{5}{|c|}{ Right } & \multicolumn{3}{|c|}{ Left } \\
\hline Gender & No. & Mean & SD & P-value & Mean & SD & P-value \\
\hline Male & 30 & 20.1 & 3.6 & \multirow[t]{2}{*}{0.70} & 20.4 & 3.7 & \multirow[t]{2}{*}{0.81} \\
\hline Female & 30 & 19.8 & 2.0 & & 20.2 & 2.9 & \\
\hline
\end{tabular}

3. Anteroposterior Length of Pedicle (Fig. 3): It is the distance from the base of pedicle to the anterior cortex of $1^{\text {st }}$ sacral vertebra 


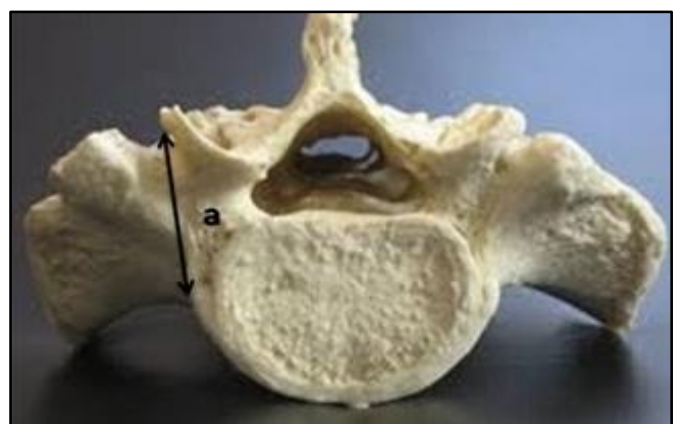

Fig. 3: (a) Antero posterior length of pedicle

Table 3: Anteroposterior length of pedicle ( $\mathrm{mm})$

\begin{tabular}{|c|c|c|c|c|c|c|c|}
\hline \multicolumn{5}{|l|}{ Right } & \multicolumn{3}{|c|}{ Left } \\
\hline Gender & No. & Mean & SD & P-value & Mean & SD & P-value \\
\hline Male & 30 & 18.3 & 6.4 & $0.003 * *$ & 17.4 & 6.4 & $0.007 * *$ \\
\hline Female & 30 & 13.7 & 5.0 & & 13.3 & 5.0 & \\
\hline
\end{tabular}

$$
\text { **significant }
$$

4. The Width of Pedicle (Fig. 4): It is perpendicular distance from anteroposterior length of pedicle length to the outer margin of the sacral canal.

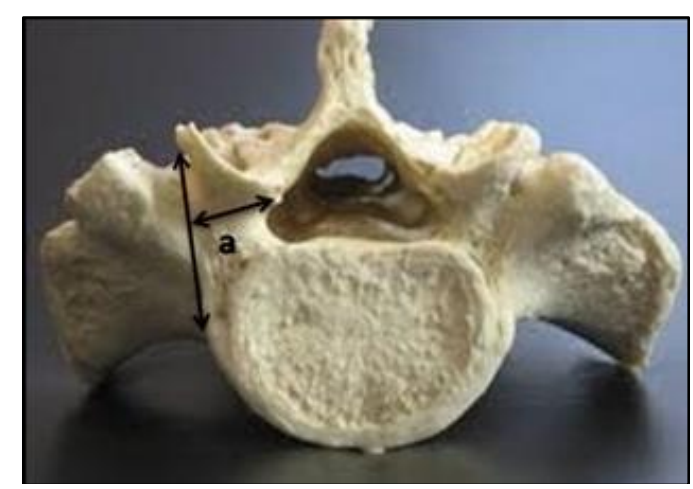

Fig. 4: (a) Width of pedicle

Table 4: Width of the pedicle (mm)

\begin{tabular}{|c|c|c|c|c|c|c|c|}
\hline \multicolumn{5}{|l|}{ Right } & \multicolumn{3}{|l|}{ Left } \\
\hline Gender & No. & Mean & SD & P-value & Mean & SD & P-value \\
\hline Male & 30 & 13.3 & 2.7 & 0.122 & 13.8 & 3.4 & 0.030 \\
\hline Female & 30 & 12.3 & 2.4 & & 11.6 & 3.9 & \\
\hline
\end{tabular}

5. Antero Posterior Diameter of Sacral ala at Lateral Margin of Posterior Sacral Foraminae (Fig. 5)

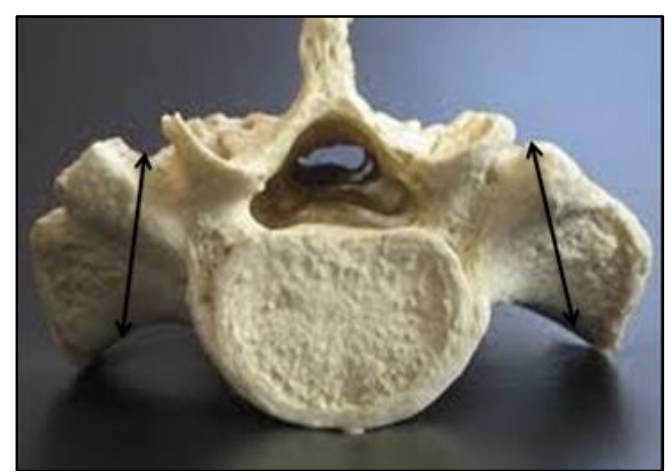

Fig. 5: Antero posterior length of ala 
Table 5: Antero posterior diameter of sacral ala at lateral margin of posterior sacral foraminae (mm)

\begin{tabular}{|c|c|c|c|c|c|c|c|}
\hline \multicolumn{5}{|c|}{ Right } & \multicolumn{3}{|c|}{ Left } \\
\hline Gender & No. & Mean & SD & p-value & Mean & SD & p-value \\
\hline Male & 30 & 31.2 & 5.6 & \multirow[t]{2}{*}{0.974} & 30.7 & 4.7 & \multirow[t]{2}{*}{0.340} \\
\hline Female & 30 & 31.2 & 4.8 & & 29.6 & 4.6 & \\
\hline
\end{tabular}

\section{Discussion}

In our study, the mean straight length of the sacrum (SH) was $105.3 \pm 1.18 \mathrm{~mm}$ and $92.0 \pm 0.63 \mathrm{~mm}$ in males and females respectively. The mean maximum width of the sacrum (SW) was $95.9 \mathrm{~mm}$ in males and $95.4 \mathrm{~mm}$ in females. SH but not the SW showed statistically significant sex differences with $P$ value 0.000 and 0.788 respectively.

In Dr.S.Manisha's ${ }^{2}$ study, the mean SH was 102.9 $\mathrm{mm}$ and $90.9 \mathrm{~mm}$ in males and females respectively whereas the mean SW was $100.40 \mathrm{~mm}$ in males and $105.7 \mathrm{~mm}$ in females. Which showed statistically significant gender differences ( $\mathrm{P}$ value 0.0001 in males and 0.017 in females).

Our study and Dr. S. Manisha's ${ }^{2}$ study falls under Dolichoheiric ${ }^{*}$ group for males and platycheiric ${ }^{\dagger}$ group for females.

In Mazumdar study ${ }^{4}$ the mean SH was $100.8 \pm 11.5$ and $87.3 \pm 7.4 \mathrm{mmin}$ males and females respectively. The mean SW was $96.3 \pm 7.4 \mathrm{~mm}$ and $95.6 \pm 5.7 \mathrm{~mm}$ in males and in females respectively. Thus Indian population showed regional variation.

Whereas Basaloglu ${ }^{5}$ reported the mean $\mathrm{SH}$ of

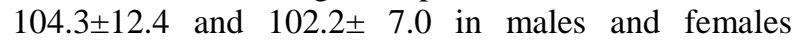
respectively. The mean SW was $102.0 \pm 10.2 \mathrm{~mm}$ and $108.4 \pm 6.0 \mathrm{~mm}$ in males and in females respectively. This study was done in western Anatolian population, thus showing racial variation.

Antero-posterior diameters of S1 in Dr. Manisha's study $^{2}$ was $29.44 \pm 2.40 \mathrm{~mm}$ in males and $29.73 \pm 2.50$ $\mathrm{mm}$ in females respectively. In the present study, the value was $30.2 \pm 0.33 \mathrm{~mm}$ and $33.0 \pm 1.81 \mathrm{~mm}$ in males and females respectively.

Mazumdar ${ }^{4}$ found $29.4 \pm 3.8 \mathrm{~mm}$ and $27.9 \pm 2.7 \mathrm{~mm}$ in male and female respectively. Basaloglu et al. ${ }^{5}$ and Arman $\mathrm{C}^{3}$ found $31.70 \pm 3.0 \mathrm{~mm}$ in males and $30.3 \pm$ $2.8 \mathrm{~mm}$ in females.

Our study showed higher values as compared to $\mathrm{Xu}^{6}$ Mazumdar, ${ }^{4}$ Dr. S. Manisha ${ }^{2}$ and was in line with Basaloglu $\mathrm{u}^{5}$ and Arman $\mathrm{C}^{3}$ study.

In the present study $1^{\text {st }}$ vertebral body height (VBH) was $27.3 \pm 2.9 \mathrm{~mm}$ and $27.6 \pm 2.7 \mathrm{~mm}$ in males and females. In Dr. S. Manisha ${ }^{2}$ it was $28.02 \pm 2.46 \mathrm{~mm}$ and $28.48 \pm 1.98 \mathrm{~mm}$ in males and females respectively. This finding was higher in the study of Basaloglu ${ }^{5}$ and Arman C. ${ }^{3}$ Our study coincided with those of Dr. S. Manisha and Xu et al.

\footnotetext{
* sacral index < 100 (up to 99.99)
}

${ }^{\dagger}$ sacral index $>106$
The S1 pedicle is fairly different from other the spinal pedicle. Values of PPH are $20.1 \pm 3.6 \mathrm{~mm}$ and $19.8+2 \mathrm{~mm}$ on right side in males and females, with $20.4 \pm 3.7 \mathrm{~mm}$ and $20.2 \pm 2.9 \mathrm{~mm}$ on left side in males and females respectively. Values of PPH and PW are lower in Indian population as compared to the population of Turkey.

The mean pedicle depth, values are less compare to Basaloglu study ${ }^{5}$ but were similar with other authors.

\section{Conclusion}

The mean anterior vertebral height and the mean posterior pedicle height were higher in males than females. The mean anteroposterior diameter of sacral alae were almost same in both the genders which can be used in determining screw length for placement at ala region.

The mean anteroposterior length of pedicle was higher on both sides in males which is an important parameter to avoid damage to the related structure by pedicle screw.

The mean width of pedicle was higher in males than females. The width of $1^{\text {st }}$ sacral pedicle is an important measurement to avoid damage to sacral canal structure by pedicle screw. Values of PPH and PW are lower in Indian population as compared to the population of Turkey. The mean pedicle depth, values are less compared to Turkey study but were similar to other studies.

\section{Research Highlights}

Our study took forth the issue of pedicle dimension for sacral screw fixation in Mumbai population which is the rare study from this region.International comparison shows our regional pedicle size difference, so most of the pedicle screw imported to India should consider Indian pedicle dimension for screw fixation especially in Mumbai, Maharashtra population. We also noticed gender differences in pedicle depth and were more in males than females.

\section{Limitation}

1. More sample size should be taken to arrive at more accurate data.

2. Different state study from India would give an overall statistical view of regional variation.

\section{Recommendation}

More sample size would give us more accurate data in various regions in India and also arrive at gender difference. This study should be correlated with CT and 
MRI scan for accurate screw placements and to avoid complication. $^{7}$

\section{Funding and Policy Aspects}

The present study was self-funded. Incorporating high diagnostic modalities like CT and MRI which increase the accuracy and reduce postoperative complication need funding. Funding from institutional level or government level will encourage the further research in India to set a cut off range of pedicle morphometry, this will definitely help the surgeon and orthopedicians to help carry less complication postoperatively.

\section{Conflict of Interest: No conflict of interest}

\section{Acknowledgment}

We would like to sincerely thank Department of Anatomy of MGM and Terna Medical College for allowing us to do our research. The ethical committee of MGM Medical College for accepting our research work. We are thankful to our professor Dr. Aruna Mukherjee who provided expertise that greatly helped us to finish our research. We also acknowledge our statistician for all statistical frameworks. We also appreciate our non-teaching staff for helping us in our research.

\section{Reference}

1. Susan S. Greys Anatomy 40th edition Churchill Livingstone Elsevier. Spain. 2008; p. 1007. 2008;9.

2. Sinha MB, Rathore M, Trivedi S, Siddiqui AU. Morphology of first pedcle of sacrum and its clinical relevance. IJHBR. 2013;1(4):234-40.
3. Arman C, Naderi S, Kiray A, Aksu FT, Y1lmaz HS, Tetik $\mathrm{S}$, Korman E. The human sacrum and safe approaches for screw placement. Journal of Clinical Neuroscience. 2009;16(8):1046-9.

4. Mazumdar S, Ray A, Mazumdar A, Majumdar S, Sinha A, Vasisht S. Sexual dimorphism and regional difference in size of sacrum: A study in Eastern India. Al Ameen $J$ Med Sci. 2012;5(3):298-307.

5. Başaloğlu H, Turgut M, Taşer FA, Ceylan T, Başaloğlu HK, Ceylan AA. Morphometry of the sacrum for clinical use. Surgical and Radiologic Anatomy. 2005;27(6):46771.

6. Xu R, Ebraheim NA, Yeasting RA, Wong FY, Jackson WT. Morphometric evaluation of the first sacral vertebra and the projection of its pedicle on the posterior aspect of the sacrum. Spine. 1995;20(8):936-40.

7. Lonstein JE, Denis F, Perra JH, Pinto MR, Smith MD, Winter RB. Complications associated with pedicle screws. JBJS. 1999;81(11):1519-28.

How to cite this article: Rathod P.R, Rathod S. P. Morphometry study of pedicle for sacral screw fixation in Navi Mumbai population. Indian J Clin Anat Physiol. 2018;5(4):525-529. 